\title{
REGIMEN FEDERAL DE ACCESO A LA INFORMACIÓN PÚBLICA
}

\author{
REGIME FEDERAL DE ACESSO A INFORMAÇÃO PÚBLICA
}

\author{
Alfonso Buteler \\ Universidad Empresarial Siglo 21- Córdoba - Argentina
}

\begin{abstract}
Resumen: É posible afirmar que el acceso a la información pública constituye un derecho humano fundamental, reconocido en la mayoría de los sistemas jurídicos comparados y supranacionales por el cual se permite a toda persona acceder a datos, registros, expedientes y a cualquier tipo de información que se encuentre en poder de autoridades públicas o privadas que lleven adelante cometidos públicos. En este contexto, el presente estudio tiene como objetivo, a partir del Decreto 1172/03 que establece el acceso a la información pública en el ámbito del Poder Ejecutivo Nacional, analizar os principales lineamientos que se han trazado con ese cuerpo normativo y las sentencias que se han ido dictando en su consecuencia. Se concluye que la negativa a brindar la información requerida constituye un acto arbitrario e ilegítimo en el marco de los principios de una sociedad democrática e implica, en consecuencia, una acción que recorta en forma severa derechos humanos. Por lo tanto, os Estados deben adecuar su ordenamiento interno a los tratados de derecho humanos "no solo deben garantizar este derecho en el ámbito puramente administrativo o de instituciones ligadas al Poder Ejecutivo, sino a todos los órganos del poder público
\end{abstract}

Palabras clave: Información; Derecho Humano Fundamental; Autoridad Pública

Abstract: It is possible to affirm that the access to the public information is a fundamental human right, recognized in most compared legal systems and supranational systemn, by which anyone is allowed to access data, records and any information that is in possession of public or private authorities to carry forward public tasks. In this context, this study aims, from Act $n^{\circ} 1172 / 03$, that establishes access to public information in the field of the Executive Power, to analyze the main guidelines have been drawn with the regulatory body and the judgments have been dictated in consequence. It is concluded that the refusal to provide the information requested constitutes an arbitrary and unlawful pactice under the principles of a democratic society and implies, therefore, an action that severely cut human rights. Therefore, the States must adapt their domestic law to human rights treaties and should not only guarantee this right in the purely administrative level or institutions linked to the Executive Power, but to all public departaments.

Keywords: Information; Fundamental Human Right; Public Authority

\section{INTRODUCCION}

El acceso a la información pública constituye un derecho humano fundamental, reconocido en la mayoría de los sistemas jurídicos comparados y supranacionales por el cual se permite a toda persona acceder a datos, registros, expedientes y a cualquier tipo de información que se encuentre en poder de autoridades públicas o privadas que lleven adelante cometidos públicos.

De esta manera, este derecho se erige dentro del Estado de Derecho en un cauce de participación ciudadana, por cuyo conducto se procura fomentar la 
transparencia de la actividad estatal y el control del ejercicio del poder público y de la corrupción pública.

Cabe destacar, que este derecho, posee un antiguo antecedente en el derecho comparado que se remonta a la Real Ordenanza Sueca sobre la libertad de prensa del año $1766 \mathrm{y}$, que a partir de entonces, se ha propagado por numerosos países conjuntamente con la democracia entre los que cabe mencionar a España (Art. 105 inc. b de su Constitución) ${ }^{1}$, Estados Unidos (Freedom of Information Act de 1966), Francia (Ley del 17 de junio de 1978), Italia (Ley del 7 de agosto de 1990) y la Unión Europea (Art. 42 de la Carta de Derechos Fundamentales) (SÁNCHEZ MORON, 2007).

El dictado del Decreto 1172/03 vino a cubrir un vacío normativo en la materia al regular lo relativo al acceso a la información pública en el ámbito del Poder Ejecutivo Nacional aunque todavía es una deuda pendiente del Congreso el dictado de una ley que sea aplicable a toda la órbita federal.

A partir de ello, en el presente trabajo procuraremos analizar los principales lineamientos que se han trazado con ese cuerpo normativo y las sentencias que se han ido dictando en su consecuencia.

\section{BREVE RESEÑA SOBRE SU EVOLUCIÓN}

a) El modelo de confidencialidad y secreto: De manera previa a la consagración normativa y constitucional del derecho de acceso a la información pública ${ }^{2}$ era una facultad de la administración pública brindar o no la información solicitada por el particular, la cual se traducía en un poder que era detentado por unos pocos (GUICHOT EMILIO, 2003).

Ese modelo de sociedad basada en el "oscurantismo" acompañó a los gobiernos desde épocas remotas y se mantuvo vigente hasta mediados del Siglo XIX, apdroximadamente. Esa situación, implicaba que la información estatal era controlaa y monopolizada por poder de turno siendo utilizada, muchas veces, con fines políticos y estratégicos alejados del interés público.

\footnotetext{
1 Esa cláusula constitucional establece el derecho de los ciudadanos a acceder a los archivos y registros administrativos, salvo que ello atentare contra la seguridad del Estado, la averiguación de los delitos o la intimidad de las personas.

2 En adelante utilizaremos la abreviatura DAIP.
} 
En esta etapa, quien pretendía el conocimiento de los actos estatales, debía acreditar la detentación de una situación jurídica subjetiva -derecho subjetivo o interés legítimo- que le permitiera ser parte en el procedimiento administrativo, debiendo explicitar las razones que lo llevaba a requerir la información. ${ }^{3}$ A su vez, ante la denegación de la misma el interesado quedaba obligado a lograr el agotamiento de la vía administrativa para recién lograr auxilio del órgano judicial.

b) El reconocimiento del derecho de acceso a la información pública: El nacimiento de la sociedad de la información y el reconocimiento del DAIP implicó una conquista que ha sido denominada como "histórica" (SANCHEZ MORON, 1995) que, a su vez, derivó en una modificación de la regla general imperante en la etapa anterior según la cual el funcionamiento administrativo y las relaciones con la administración pública y el ciudadano bajo "secreto".

Es que, en definitiva, se advirtió que la consolidación del Estado Democrático de Derecho dependía, en gran medida, del respeto a ese derecho fundamental y justamente, esa circunstancia, es la que motivó que el mismo sea actualmente reconocido en la mayoría de los sistemas jurídicos comparados ${ }^{4} y$ supranacionales por los cuales se permite a toda persona acceder a datos, registros, expedientes y a cualquier tipo de información que se encuentre en poder de autoridades públicas o privadas que lleven adelante cometidos públicos, sin aducir las razones para ello.

Así, en la actualidad, la presencia del ciudadano permite la fiscalización de las decisiones públicas y el conocimiento de las mismas evitando, de ese modo, el oscurantismo estatal, posibilitando el control de la corrupción estatal y el

\footnotetext{
3 Valga destacar que el art. 2 inc. c) de la Ley 19549 (B.O., 27/04/1972) autoriza al Poder Ejecutivo Nacional a "determinar las circunstancias y autoridades competentes para calificar como reservadas o secretas las actuaciones, diligencias, informes o dictámenes que deban tener ese carácter, aunque estén incluidos en actuaciones públicas". Por otra parte, el art. 38 del Reglamento de la Ley de Procedimientos Administrativos (Decreto 1759/72) dispone que "La parte interesada, su apoderado o letrado patrocinante podrán tomar vista del expediente durante todo su trámite, con excepción de aquellas actuaciones, diligencias, informes o dictámenes que, a pedido del órgano competente y previo asesoramiento del servicio jurídico correspondiente, fueren declarados reservados o secretos mediante decisión fundada del respectivo subsecretario del ministerio o del titular del ente descentralizado de que se trate.

4 Cfr. SÁNCHEZ MORON, M., op. cit., pag. 454. Sobre el desarrollo de ese derecho en el sistema comparado puede verse: BASTERRA, Marcela I., op. cit., pag. 207 y ss.; TRAVIESO, Florencio, "El derecho de acceso a la información pública. Principios y fundamentos en un reciente fallo", E.D., 197:297.
} 
desempeño de los funcionarios dentro de los márgenes previstos en la Ley de Ėtica Pública ${ }^{5}$. Por tales razones, la Convención Interamericana contra la Corrupción ${ }^{6}$ y la Convención de Naciones Unidas contra la Corrupción ${ }^{7}$ se han hecho eco de la cuestión al imponer a los Estados Partes el deber de instaurar en los sistemas internos mecanismos que permitan el desenvolvimiento del DAIP.

En seguimiento de esa tendencia mundial y más allá del reconocimiento constitucional y normativo especifico ${ }^{8}$, en nuestro país se dictó hace unos años el Decreto $1172 / 03^{9}$ que -entre otros aspectos ${ }^{10}$ - vino a regular lo relativo al acceso a la información pública en el ámbito del Poder Ejecutivo Nacional. Dicha norma, dispone en sus considerandos que aquel derecho constituye un "prerrequisito de la participación que permite controlar la corrupción, optimizar la eficiencia de las instancias gubernamentales y mejorar la calidad de vida de las personas al darle a éstas la posibilidad de conocer los contenidos de las decisiones que se toman día a día para ayudar a definir y sustentar lo propósitos para una mejor comunidad".

Es que como lo señaló el juez Fayt al resolver la causa "Verbitsky", "la información condiciona la existencia y las actividades de cada sociedad y la participación resulta imposible sin ella" a lo que debe sumarse la importancia estratégica de la misma en el diseño de políticas públicas y privadas.

\footnotetext{
Ley 25.188, B.O. 01/11/1999.

Aprobada por Ley 24.759, B.O. 19/01/1997.

Aprobada por Ley 26.097, B.O., 09/06/06.

8 En el orden federal argentino, el acceso a la información ha sido enunciado por diversas leyes específicas. Entre otras, cabe destacar las siguientes: Ley de Radiodifusión $\mathrm{n}^{\circ} 22.285$, art. 18 (B.O. 19/09/1980); Ley de Régimen de Energía eléctrica $\mathrm{n}^{\circ} 24.065$, art. 56 (B.O. 16/01/1992); Ley Marco Regulatorio del Gas natural $n^{\circ}$ 24.076, art. 52 (B.O. 12/06/1992); Ley de Administración financiera y de control, $\mathrm{n}^{\circ}$ 24.156, art. 4 (B.O. 29/10/1992); Ley de defensa del Consumidor $\mathrm{n}^{\circ}$ 24.240, art. 4 (B.O. 15/10/1993); Ley Administración Federal de los Ingresos Públicos, $n^{\circ}$ 25.152, art. 8 (B.O. 29/09/1999); Ley de Ética Pública $n^{\circ} 25.188$, art. 2 (B.O. 01/11/1999); Ley de Policita Ambiental Nacional $n^{\circ} 25.675$, arts. 16/18 (B.O. 28/11/2002); Ley del Régimen de Libre Acceso a la Información Pública Ambiental nº 25.831 (B.O. 07/01/2004). Todas ellas, matices mediante, hacen referencia a la obligación, al modo y al deber de informar a los usuarios, consumidores, administrados y/o ciudadanos.

9 B.O. 4/12/2003. A su vez, mediante la Resolución conjunta 3/2008 de la Fiscalía de Control Administrativo y la Resolución conjunta 1/2008 de la Secretaría de Gabinete y Relaciones Parlamentarias se aprobó el procedimiento de tramitación de las denuncias por incumplimiento de las obligaciones previstas en el Reglamento General del Acceso a la Información Pública para el Poder Ejecutivo Nacional.

10 También regula lo relativo al régimen de audiencias públicas, el lobby, la participación en la elaboración de normas generales, etc. Sobre ese tema puede consultarse: BRUNO DOS SANTOS, Marcelo A., FERNÁNDEZ LAMELA, Pablo M., y LOPEZ OLVERA, Miguel Alejandro, "La participación pública y el acceso a la información: herramientas para mejorar la calidad institucional. Comentarios al Decreto 1.172/03", Revista RAP, n 315, pag. 91 y ss.
}

REVISTA DO DIREITO UNISC, SANTA CRUZ DO SUL №. 44 | p.192-219| SET-DEZ 2014 
c) La información pública positiva:

Amén de la importancia de lo apuntando precedentemente en cuanto al desarrollo que ha tenido el DAIP, debe destacarse que en la actualidad ya no alcanza con que el Estado permita el acceso de los interesados a la información pública o con que se establezcan herramientas procesales para los casos en que la misma es retaceada, total o parcialmente. Pues, un nuevo concepto se viene abriendo camino desde hace unos años: la información pública positiva. El mismo implica que va a ser a propia administración pública quien por su propia iniciativa o por imposición legal quien deba poner en conocimiento de la ciudadanía a través de su publicación cierta información "mínima" que se considere útil en un sistema democrático y trasparente (GUICHOT, 2003), la cual debe ir aumentando gradualmente. Sobre este tema volveremos más adelante.

\section{FUNDAMENTO CONSTITUCIONAL}

El derecho al acceso a la información pública tiene fundamento constitucional tanto en las cláusulas de la Carta Magna como en los instrumentos internacionales incorporados a la Ley Fundamental por la vía del art. 75 inc. 22, luego de la reforma de 1994.

Entre los primeros, cabe destacar, el art. 1 en cuanto establece el sistema republicano de gobierno e impone la publicidad de los actos públicos y el art. 33, en tanto esta última disposición constitucional "proporciona fundamento suficiente a la obligación de dar publicidad a todos los actos de gobierno dado que, esa norma, reconoce los derechos que emanan de la soberanía del pueblo" (GELLI, 2003).

El art. 38 de la C.N., por su parte, brinda apoyatura constitucional en lo relativo a los partidos políticos al exigir que se garantice a los mismos el acceso a la información pública.

A su vez, el art. 41 luego de consagrar los derechos relativos al medioambiente obliga a las autoridades a proteger el mismo y a la información de carácter ambiental y el art. 42, por otro lado, establece el derecho de los consumidores y usuarios de bienes y servicios a una información adecuada y veraz. 
En lo que hace a los instrumentos internacionales que detentan jerarquía constitucional, reconocen el derecho de acceso a la información pública la Convención Americana sobre Derechos Humanos (Art. 13.1), la Declaración Universal de Derechos Humanos (Art. 19) y el Pacto Internacional de Derechos Civiles y Políticos (Art. 19 inc. 2), al establecer que todo individuo tiene derecho a recibir información y difundirla por cualquier medio.

Valga destacar, por último, el carácter operativo de este derecho, independientemente de las previsiones normativas que existan sobre la posibilidad de conocer la información pública a nivel nacional, provincial o municipal.

\section{OBJETO DE ACESSO}

El universo de la información pública se halla compuesto por toda aquella que pueda ser comunicable (CARRANZA TORRES; PALAZZI, 2003); es decir comprende todos los expedientes, archivos, registros, bases de datos y documentos escritos, fotografías, grabaciones, etc., que se encuentren en poder de autoridades públicas o privadas que realizan un cometido público o que reciben un subsidio estatal en los términos del Decreto 1172/03 (BASTERRA, 2005). El acceso a la información pública implica, entonces, la posibilidad de conocer los documentos administrativos, la normativa administrativa y los procedimientos que se tramiten ante las autoridades públicas y la que se halla en manos privadas, con las salvedades a que haremos referencia mas adelante.

\section{PRINCIPIOS APLICABLES}

La esencia adjetiva del pedido de acceso a la información pública hace aplicables algunos principios propios del procedimiento administrativo general y que resultan insoslayables para el correcto desenvolvimiento de este cauce específico de participación ciudadana. ${ }^{11}$ Entre ellos se destacan los siguientes:

${ }^{11}$ Para ampliar puede verse: BUTELER, Alfonso y CORVALAN, Juan G, "'Los principios del procedimiento informativo", El Derecho, Suplemento de Derecho Administrativo, 18/12/2008, pag. $1 / 4$. 
1. Juridicidad: Este principio significa que todo el accionar de la administración pública debe adecuarse al ordenamiento jurídico que se halla integrado por todo el bloque de juridicidad compuesto por la Ley Fundamental, los tratados internacionales con jerarquía constitucional (art. 75 inc. 22), leyes, reglamentos, etc (COMADIRA, 2002)

Sobre tal cuestión, ha señalado la Corte Suprema de Justicia de la Nación que "es inherente al ejercicio de la actividad administrativa que ésta sea desempeñada conforme a la ley, pues constituye una de las expresiones del poder público estatal, que tiene el deber de someterse a ella. En esa sujeción al orden jurídico radica una de las bases del estado de derecho, sin la cual no sería factible el logro de sus objetivos". ${ }^{12}$

De esta manera, la concreción de tal principio en el ámbito del procedimiento informativo implica que la administración pública debe respetar el bloque de juridicidad vigente, el cual también se integra, lógicamente, con las normas que rigen el acceso a la información.

2. Verdad jurídica objetiva: Según este principio, mediante el desenvolvimiento del procedimiento administrativo la autoridad pública debe perseguir la verdad material, independientemente de la manera en que las cuestiones hayan sido alegadas por las partes (COMADIRA, 2002), dado que su actividad se dirige íntegramente a la protección del interés público ${ }^{13}$.

El mentado principio, se encuentra receptado en el ámbito nacional en el art. 2 inc. f) punto 2 de la Ley 19.549 y en el art. 48 del R.N.P.A. ${ }^{14}$ A su vez, como lo destacado Comadira, esa es la inteligencia que se desprende del art. 7 inciso c) de la mentada ley cuando dispone que al dictar un acto administrativo la autoridad pública "debe decidir todas la peticiones formuladas, pero puede involucrar otras no propuestas".

Cabe poner de resalto, que esa directiva del alcanzar la verdad material no solo se dirige a la persona estatal sino también al propio solicitante de la información pública quien debe colaborar con la administración con ese propósito.

${ }_{12}$ Fallos, 315:2771, (1992), "Naviero de la Serna de López Elena María c. Bauhoffer Martha Beatriz".

${ }_{13}$ Cfr. ESCOLA, Héctor J., Tratado general de procedimiento administrativo, Buenos Aires, Depalma, 1973, pag. 127; FIORINI, Bartolomé A., Procedimiento administrativo y recurso jerárquico, Buenos Aires, Abeledo-Perrot, 1971, $2^{\text {a }}$ Ed. ampliada y actualizada, pag. 58.

${ }^{14}$ Reglamento Nacional de Procedimiento Administrativo, Decreto 1752/72.

REVISTA DO DIREITO UNISC, SANTA CRUZ DO SUL №. 44 | p.192-219 | SET-DEZ 2014 
De ese modo, lo ha entendido la propia Corte Suprema Nacional en la causa "Darusse de Fernández" 15 al señalar que "el recurrente concurre como colaborador en la elaboración de la decisión administrativa aun cuando defiende sus derechos subjetivos".

3. Formalismo moderado o informalismo a favor del administrado: Este principio, se encuentra expresamente receptado en art. $1^{\circ}$ inc. c) de la L.N.P.A. al excusar al administrado de observar todas aquellas exigencias formales que puedan ser cumplidas con posterioridad a su presentación y sus diversas manifestaciones procedimentales.

A su vez, el art. 5, inc. d) del R.N.P.A. establece que el órgano competente deberá "Señalar, antes de dar trámite a cualquier petición, los defectos de que adolezca, ordenando que se subsanen de oficio o por el interesado dentro del plazo razonable que fije, disponiendo de la misma manera las diligencias que fueren necesarias para evitar nulidades".

De esta manera, dicho principio no se traduce en la inexigibilidad de las formas "sino en relativización de ellas en beneficio inmediato de los administrados, siempre que no sean esenciales" (COMADIRA, 2000).

En el caso de la información pública ello no significa que no pueda exigirse a quien solicita la misma que cumplimente con ciertos recaudos formales como es la forma escrita de la solicitud, sino que los mismos no se constituyan en un valladar para acceder a su conocimiento. Por la aplicación de este mismo principio, tampoco puede obligarse al interesado a contar con patrocinio letrado ${ }^{16}$.

En tal orden de ideas, el art. 11 del Decreto 1172/2003 establece que la solicitud de información debe efectuarse por escrito, con la identificación del requirente, sin estar sujeta a ninguna otra formalidad para luego agregar que "No puede exigirse la manifestación del propósito de la requisitoria. Debe entregarse al solicitante de la información una constancia del requerimiento".

Además, en el supuesto en que una solicitud no sea precisa la administración deberá colaborar con el solicitante a los fines de que aclare su pretensión, incluso facilitándole la documentación que se lo permita.

\footnotetext{
${ }^{15}$ Fallos, 308:633, (1986), "Darusse de Fernández, Graciela"

${ }^{16}$ Cfr. Art. $6^{\circ}$ Decreto $1172 / 03$.
}

REVISTA DO DIREITO UNISC, SANTA CRUZ DO SUL №. 44 | p.192-219 | SET-DEZ 2014 
4. Oficialidad: La aplicación de este principio -receptado en el art. 1 inc. a) de la L.N.P.A.- trae aparejado que sea la autoridad administrativa quien deba adoptar los recaudos conducentes a la impulsión del procedimiento (COMADIRA, 2002).

Esta regla, no es absoluta sino que existen cuestiones que deben ser instadas por los particulares interesados, como ocurre con quien solicita la información pública. En tal inteligencia, el art. $4^{\circ}$ del R.N.P.A. dispone que "Todas las actuaciones administrativas serán impulsadas de oficio por el órgano competente, lo cual no obstará a que también el interesado inste el procedimiento. Se exceptúan de este principio aquellos tramite en los que medio solo el interés privado del administrado, a menos que, pese a ese carácter, la resolución a dictarse pudiere llegar a afectar de algún modo el interés general”.

5.- Debido procedimiento previo: El art. 7 inc. d) de la ley 19.549 exige, que previo a la emisión del acto administrativo, se lleven a cabo los procedimientos previstos por la normativa vigente y los que resulten implícitos del ordenamiento jurídico. También, se prescribe como esencial, el cumplimiento del dictamen proveniente de los servicios jurídicos permanentes, cuando el acto pudiere afectar derechos subjetivos e intereses legítimos. Por su parte, el art. 14 inc. b) del mismo cuerpo legal determina la nulidad absoluta e insanable en caso de violación de las formas esenciales, entre las cuales se ubica el procedimiento.

Consideramos que la sanción de nulidad impuesta por la norma citada resulta acertada pues, como lo advierte Comadira (2003) el debido proceso adjetivo, aparece como correlato de la garantía de defensa constitucional del art. 18 en sede administrativa, lo que implica, que debe cumplirse inevitablemente cuando los derechos de los particulares puedan resultar afectados. Entonces, es pertinente afirmar que del texto de la L.N.P.A. se desprende que el acto administrativo se encuentra vacuo sin el procedimiento (COVIELLO, 2002) y que los defectos de éste se adhieren al acto definitivo impregnándolo de nulidad.

De esta manera, el procedimiento administrativo se instituye no solamente para proteger los intereses de los particulares sino como un mecanismo de protección del interés público.

Una variante de dicho principio lo constituye el derecho de defensa adjetivo como un reflejo en sede administrativa de la garantía constitucional receptada en 
el art. 18 de la Ley fundamental. Ello implica, el derecho a ser oído, a ofrecer pruebas, a ampliar fundamentos en los recursos que se interpongan, etc.

Este principio adquiere relevancia dentro del procedimiento de acceso a la información para aquellos casos en que el administrado requiere su conocimiento para impugnar un acto administrativo -sea de alcance particular o general-, pues de no brindarse la misma se le impedirá el ejercicio de una debida defensa de los intereses comprometidos en el dictado de la medida.

En tal orden de ideas, la C.N.C.A.F. en "Carbone" ${ }^{17}$ hizo lugar a un amparo declarando la ilegitimidad manifiesta, por la violación en sus formas esenciales, de la resolución a través de la cual, se había denegado el recurso jerárquico interpuesto por la actora pues, el acto se había emitido violando el derecho de defensa del administrado en cuanto, no se le había permitido tomar vista de las actuaciones a los fines de mejorar los fundamentos del recurso interpuesto.

Amén de los que acabamos de mencionar existen, además, principios específicos del procedimiento informativo cuya incidencia debe manifestarse a lo largo de todo su desarrollo.

1.- Congruencia: La información que brinda la persona pública o privada -que se encuentre obligada normativamente en tal sentido- debe ser conteste con la solicitada por el requirente, pues si se otorgan datos generales o abstractos se estará vedando solapadamente el DAIP.

2.- Completitud: Además de ser congruente, la información que se brinda debe ser completa y no parcializada, salvo que se encuentre limitada por norma expresa, tal como lo ordena el art. 4 del Decreto 1172/03.

Asimismo, el art. 17 de dicho cuerpo normativo prevé que en el caso que existiere un documento que contenga información parcialmente reservada, los sujetos enumerados en el art. 2 deben permitir el acceso a la parte de aquella que no se encuentre contenida entre las excepciones detalladas en el artículo 16.

Sin embargo, debe tenerse presente que si la información pública está parcialmente limitada y el otorgamiento de la que se puede brindar induce a confusión, no se entiende o pierde sentido puede ser limitada en su totalidad por la autoridad estatal.

${ }^{17}$ C.N.C.A.F., Sala III, 14/11/89, "Carbone, Edgardo Guillermo, c/ C.O.N.E.T. s/ amparo".

REVISTA DO DIREITO UNISC, SANTA CRUZ DO SUL NN. 44 | p.192-219 | SET-DEZ 2014 
3.- Adecuación: Asimismo, debe aportarse toda aquella información pública que guarde directa vinculación con el objeto de petición, habida cuenta que una actitud contraria del sujeto pasivo obligado puede derivar en el cercenamiento del derecho de acceso ${ }^{18}$;

4.- Gratuidad: A los fines de acceder a la información no puede exigirse al requirente el pago de tasas, aranceles o contribuciones, ni tampoco contar con patrocinio letrado obligatorio. En tal sentido, el art. 9 de Decreto 1172/03 prescribe que el acceso público a la información es gratuito en tanto no se requiera su reproducción pero si pretende sacar copias éstas son a costa del solicitante;

5.- Oportunidad: La información debe ser otorgada en un plazo razonable que deberá determinarse en cada supuesto por la reglamentación vigente, pues de lo contrario la demora puede implicar el aniquilamiento del derecho ${ }^{19}$. En caso de no preverse un plazo consideramos que debe aplicarse el plazo de 10 días establecido en el art. 1 inc. e) apart. 4 de la L.N.P.A.

6.- Veracidad: La información que se brinda debe ser verdadera y auténtica ${ }^{20}$, siendo responsable de ello el funcionario que se encuentra obligado a brindarla. Cabe destacar que este principio goza de jerarquía constitucional en lo relativo los servicios públicos de conformidad a lo establecido en el art. 42 C.N. sean estos prestados por el propio Estado o por concesionarios o licenciatarios.

7.- Igualdad: El principio de la igualdad tiene raigambre constitucional por su recepción expresa en el art. 16 de la Ley Fundamental. La proyección del mismo sobre el procedimiento administrativo de acceso a la información pública se traduce en no denegar la información que ha sido dada a otro requirente. Tampoco, puede retacearse la información basada en criterios a priori discriminatorios como aquellos basadas en el origen nacional, máxime teniendo en cuenta el carácter universal de este derecho, salvo que esa limitación aparezca como razonable en el caso concreto. Por su parte, la Corte Nacional ha señalado que cuando se impugna una categoría infraconstitucional basada en el origen nacional "corresponde considerarla sospechosa de discriminación y

\footnotetext{
${ }^{18}$ Cfr. Art. $4^{\circ}$ Decreto $1172 / 03$

${ }_{19}$ Si la información se solicita, por ejemplo, para impugnar un acto administrativo dictado en el marco de un procedimiento licitatorio y la misma se brinda una vez vencidos los plazos para interponer los recursos la información será inútil. Cfr. Art. $4^{\circ}$ Decreto 1172/03
}

${ }^{20} \mathrm{Cfr}$. Art. $4^{\circ}$ Decreto $1172 / 03$. 
portadora de una presunción de inconstitucionalidad que corresponde a la demandada levantar"21.

Tal como lo ha destacado, Gelli existen elementos tales como la raza, el sexo, la nacionalidad, la edad, que poseen una fuerte presunción de discriminación arbitraria. Esta autora señala que en estos casos debe haber un control de fuerte de razonabilidad en razón de que existe una cierta presunción de inconstitucionalidad (GELLI, 2003). Este derecho se encuentra garantizado por el art $7^{\circ}$ del Decreto $1172 / 03$

En el mismo sentido, se ha expedido dentro del derecho comunitario la Recomendación del Comité de Ministros del 21 de febrero de 2002 en su art. 3 mediante el cual señaló que toda persona es titular del derecho de acceso, sin discriminación alguna, incluida la de origen nacional.

8.- Universalidad: Debe brindarse la información a cualquier persona que la solicite sin limitación. Por tal motivo, resulta aconsejable que el derecho a acceder a la información pública debe ser extendido a todos los ciudadanos (MENDEZ; PALAZZI, 1999), por tratarse de un derecho de titularidad universal (GAMERO CASADO; FERNÁNDEZ RAMOS, 2007), criterio que ha sido seguido por los ordenamientos de Estados Unidos, Francia, Canadá, Brasil y Colombia (DIAZ CAFFERATA, 2007) sin poder exigirse ni siquiera, la justificación de las razón que lleva al interesado a pedirla.

Esta solución, afortunadamente ha sido plasmada en el Decreto 1172/03 en su art. $6^{\circ}$ al establecer que "Toda persona física o jurídica, pública o privada, tiene derecho a solicitar, acceder y recibir información, no siendo necesario acreditar derecho subjetivo, interés legítimo ni contar con patrocinio letrado".

Tal circunstancia y la amplitud con que ha sido formulado este derecho, permite sostener que los extranjeros también detentan el derecho para requerir la información pública, de conformidad a lo dispuesto por el art. 20 C.N. en cuanto establece que gozan de los mismos derechos que los ciudadanos argentinos (ZARINI, 1999).

9.- Accesibilidad: El conocimiento de la información debe ser inmediata y sin retaceos. En tal orden de ideas, el art. 10 del art. 10 del Decreto 1172/03 dispone que Los sujetos en cuyo poder obre la información deben prever su

\footnotetext{
${ }^{21}$ Fallos: 327:5118 "Hooft".
} 
adecuada organización, sistematización y disponibilidad, asegurando un amplio y fácil acceso. La información debe ser provista sin otras condiciones más que las expresamente establecidas en el presente. Asimismo deben generar, actualizar y dar a conocer información básica, con el suficiente detalle para su individualización, a fin de orientar al público en el ejercicio de su derecho.

10. Flexibilidad: Debe facilitarse al máximo el acceso a la información. Ello exige que las normas establezcan un modo lo más sencillo posible de ejercicio del derecho y que los funcionarios o empleados públicos realicen buenas practicas administrativas, evitando que la excesiva burocracia termine frustrando la esencial del derecho e implementado para ello el uso de las nuevas tecnologías.

\section{TITULARIDAD DEL DERECHO INFORMATIVO}

Resulta aconsejable que el derecho a acceder a la información pública sea extendido a todos los ciudadanos, por tratarse de un derecho de titularidad universal, criterio que como vimos ha sido seguido por muchos ordenamientos del derecho comparado sin poder exigirse ni siquiera la justificación de las razones que llevan al interesado a pedirla.

Esta solución, afortunadamente ha sido plasmada en el Decreto 1172/03 en su art. $6^{\circ}$ al establecer que "Toda persona física o jurídica, pública o privada, tiene derecho a solicitar, acceder y recibir información, no siendo necesario acreditar derecho subjetivo, interés legítimo ni contar con patrocinio letrado".

\section{LEGITIMACIÓN}

Ahora bien, del hecho de que una persona sea titular del derecho informativo no puede derivarse sin más, la circunstancia de que posea siempre y en todos los casos legitimación activa para requerirla ya que ello dependerá de la naturaleza de la información que se solicita y de los derechos que pueda comprometer la misma. Pues, por ejemplo, no podrá solicitarse el acceso a un expediente administrativo en donde se está tramitando un sumario administrativo a un tercero pues se estaría afectado su derecho a la intimidad. Ello revela que si 
bien la legitimación es amplia habrá que adecuar esa regla a cada caso particular.

La cuestión relativa a la legitimación activa en materia de información pública implica un cambio en la concepción tradicional del derecho administrativo nacional y local que solo tutelaba la situación jurídica subjetiva de aquellas personas que detentaban un derecho subjetivo, un interés legitimo o un derecho colectivo, relevando a la figura del interés simple a una simple denuncia a la administración.

En materia de acceso a la información pública, en cambio, cualquier persona -aún la que es titular de un interés simple- se encuentra habilitada para requerirla $y$, en caso de que sea denegada o brindada parcialmente, puede utilizar todos los mecanismos administrativos y judiciales previstos al efecto en el ordenamiento jurídico federal.

En lo hace a la legitimación pasiva, entre los sujetos obligados a proporcionar la información se encuentran todas las administraciones públicas centralizadas, descentralizadas, entidades autárquicas, autoridades de control, empresas y sociedades estatales, universidades nacionales, personas públicas no estatales en lo que hace al cometido público delegado, e incluso empresas privadas que tengan a su cargo cometidos públicos como los concesionarios de servicios públicos.

A esta nómina, el Decreto 1172/03 agrega las organizaciones privadas a las que se hayan otorgado subsidios o aportes provenientes del sector público nacional, así como a las instituciones o fondos cuya administración, guarda o conservación esté a cargo del Estado Nacional a través de sus jurisdicciones o entidades y a las empresas privadas a quienes se les hayan otorgado mediante permiso, licencia, concesión o cualquier otra forma contractual, la prestación de un servicio público o la explotación de un bien del dominio público

Se ha señalado, desde la doctrina, que la reglamentación nacional no rige para las Universidades Nacionales en virtud de su carácter autónomo establecido por el art. 75 inc 19 de la $C N$ y por la Ley de Educación Superior ( $N^{0}$ 24.521) (BRUNO DOS SANTOS; FERNÁNDEZ LAMELA; LOPEZ OLVERA, 2004). Cabe apuntar, que discrepamos con esa opinión en tanto entendemos que el carácter autónomo no redime a las casas de estudio de brindar la información a los 
ciudadanos que la requieran en tanto integran la organización del Poder Ejecutivo Nacional. Además, mas allá de esa disquisición el carácter operativo del derecho fundamental comprometido obliga a permitir su acceso.

\section{LIMITACIONES}

Como casi todos los derechos, el de acceso a la información pública no es absoluto sino que puede ser reglamentado y limitado por el legislador siempre que sea respetado el valladar de la inalterabilidad y razonabilidad impuesto por el art. 28 de la C.N.

Las limitaciones que se dispongan al derecho de acceso a la información pública son de carácter excepcional y, por ello, deben ser dispuestas por la autoridad competente ${ }^{22}$, declaradas expresamente por ley, reglamento o acto administrativo, estar debidamente fundadas (BRUNO DOS SANTOS; FERNÁNDEZ LAMELA; LOPEZ OLVERA, 2006), respetar el principio de publicidad, y su interpretación es de carácter restrictivo (GAMERO CASADO, 2005), de modo tal que permitan alcanzar el principio de trasparencia de la administración pública (SÁNCHEZ MORON, 2007).

Además, resulta aconsejable que en aquellas hipótesis en que se disponga expresamente la reserva o limitación de una información se lo haga por tiempo determinado y razonable, aspecto en que desafortunadamente ha guardado silencio el Decreto 1172/03.

Ingresando a las limitaciones concretas, debe decirse que en razón del interés público puede restringirse el acceso a aquella información cuyo conocimiento pueda comprometer:

a) La seguridad o la defensa nacional (BASTERRA, 2005);

b) El secreto de Estado;

c) La investigación de delitos o la salud pública;

d) Las estrategias de defensa en juicio de la administración ${ }^{23}$;

e) La confidencialidad en el manejo de negociaciones internacionales;

\footnotetext{
${ }^{22}$ El art. 13 del Decreto 1172/03 establece que "La denegatoria debe ser dispuesta por un funcionario de jerarquía equivalente o superior a Director General"

${ }^{23}$ Cfr. Art 16 inc. f) Decreto 1172/03.
}

REVISTA DO DIREITO UNISC, SANTA CRUZ DO SUL No. 44 | p.192-219 | SET-DEZ 2014 
f) La política exterior ${ }^{24}$.

g) La eficacia de la administración, por ejemplo si va a disponer una investigación.

h) Los actos políticos (SÁNCHEZ MORON, 2007);

i) El desenvolvimiento del sistema bancario.

j) Los mecanismos de control público.

A su vez, a causa del interés privado puede vedarse el acceso a aquella información cuyo conocimiento tenga la potencialidad para comprometer:

a) El secreto profesional, empresarial, científico, sacerdotal o comercial;

b) El derecho a la intimidad;

c) La confidencialidad de un dato ${ }^{25}$;

d) El derecho a la vida o la integridad física de una persona ${ }^{26}$. En esta última hipótesis puede impedirse el acceso a documentos que contengan datos personales siempre y cuando el que lo solicite no sea el titular de los mismos.

En definitiva, tanto en las limitaciones que obedecen al resguardo del interés público como las que protegen al interés privado, nos encontramos frente a la colisión de derechos que en caso de ser necesario deberá ser ponderado por el juez a los fines de dilucidar qué interés debe prevalecer en el caso concreto.

En el primer supuesto, se enfrenta el derecho del particular a conocer la información y el interés público comprometido en la limitación o reserva de la información. Aquí, parece apropiado inclinar la balanza en caso de duda a favor del particular $\mathrm{y}$, por consiguiente, permitirle el acceso a la información que solicita.

En cambio, consideramos cuando el acceso a la información sea potencialmente capaz de violentar derechos de particulares como la intimidad, la salud, la vida, etc., la balanza debe inclinarse en contra del acceso a la información.

\section{MECANISMOS DE PROTECCIÓN}

\footnotetext{
${ }^{24}$ Cfr. Art 16 inc. a) Decreto 1172/03.

${ }^{25}$ En este caso no se podrá acceder a aquella información que se encuentre en un registro pero que por vía de habeas data ha sido sustraído de su conocimiento genera. Sobre el punto vid. BASTERRA, Marcela, "El habeas data" en AA.VV. Derecho procesal constitucional, (Manili, Pablo L., coord.), Buenos Aires, Edit. Universidad, 2005, pag. 151.

${ }^{26}$ Crf. Art 16 inc. j) Decreto 1172/03.
}

REVISTA DO DIREITO UNISC, SANTA CRUZ DO SUL №. 44 | p.192-219 | SET-DEZ 2014 
Para que el derecho al acceso a la información pública adquiera eficacia resulta preciso que se instrumenten los conductos administrativos y jurisdiccionales que permitan hacer exigible ese derecho.

En el ámbito nacional, el Decreto 1172/03 establece que en caso de que la información sea denegada la vía idónea para obligar a la administración a proveerla es el art. 28 de la Ley 19.549, esto es el amparo por mora.

Esa premisa nos lleva a plantearnos el interrogante de si estamos frente a un amparo por mora "especial". Creemos que la respuesta es negativa dado que el Decreto 1172/03 no hace alusión al "amparo por mora" sino al mecanismo previsto en el art. 28 de la LNPA., lo que implica que estamos frente al mismo supuesto. ${ }^{27}$

A los efectos de poder determinar su idoneidad como medio de tutela, debe tenerse presente que el objeto del amparo por mora es el mandato de un pronto despacho a la administración para que se expida o de curso a las actuaciones administrativas ${ }^{28}$, es decir una obligación de hacer, con lo cual la orden de brindar la información que se requiere al Poder Judicial constituye una obligación de dar. A partir de ello, debemos concluir que ese mecanismo resulta inapropiado para encausar ese tipo de pretensiones.

En esa línea interpretativa se falló la causa "Asociación por los Derechos Civiles"29, que se trataba de una demanda de amparo promovida frente a la denegatoria expresa al pedido de acceso a la información realizado ante Jefe de Gabinete de Ministros de la Nación a los fines de conocer el contenido de ciertas actas del directorio de Radio y Televisión Argentina Sociedad del Estado. Allí, la Cámara en lo contencioso administrativo federal estimó que la vía del art. 28 de la L.N.P.A. no tenía el alcance de exigir a la Administración que se pronuncie en un

${ }^{27}$ Como se sabe, también se puede pedir el acceso a información que se halle en manos de particulares que se encuentren comprendidos como sujetos pasivos por el Decreto 1172/03. En ese caso, según la solución que se propone normativamente, esto es la utilización del amparo por mora, sería inadecuada dado que este remedio de pronto despacho judicial solo puede utilizarse en contra de autoridades publicas, y en la mayoría de los casos se requiere la titularidad de un derecho subjetivo o de un interés legítimo para su procedencia.

28 Cfr. SAMMARTINO, Patricio M.E., "El amparo por mora de la administración" en AA.VV., Derecho procesal constitucional, (Pablo. L. Manili Dir.), Buenos Aires, Ed. Universidad, 2005, p. 100; IVANEGA, Miriam M., "El amparo por mora", en A.A.V.V., Amparo, medidas cautelares y otros procesos urgentes en la justicia administrativa, obra conjunta, Juan Carlos Cassagne (Director), Buenos Aires, Lexis Nexis, 2007, p. 93.

${ }^{29}$ Sentencia del 10/05/2011. 
sentido o en otro, sino tan sólo que se expida, en tanto su estrecho ámbito de conocimiento no permite controlar la legalidad de la respuesta brindada, que debe eventualmente ser cuestionada por los cauces pertinentes.

De la misma manera se había pronunciado dicho tribunal in re "Taboada Mussi" ${ }^{30}$ al sentenciar que:

\begin{abstract}
Con el amparo por mora no puede perseguirse otra cosa que no sea obligar a la administración a que emita un dictamen o una resolución de mero trámite o de fondo. El propósito perseguido no puede ser otro que la obtención de una orden de pronto despacho y tal pretensión resulta objetivamente satisfecha más allá de que se acceda al reclamo del fondo que la sustenta (IVANEGA, 2007).
\end{abstract}

A su vez, debe quedar en claro que esa norma del Decreto 1172/03 no se refiere a los supuestos en donde la negativa de brindar la información es expresa y clara, con lo cual, en esos casos, la vía del amparo por mora no sería tampoco la correspondiente.

Entonces, si la respuesta es que ese remedio no resulta idóneo para la tutela del DAIP -en ambos supuestos tratados- debemos indagarnos sobre cuál es la vía que debe utilizarse. Esa problemática expuesta ha hecho que en la práctica se acuda a otros instrumentos tales como la diligencia preliminar, la demanda autónoma de información y la acción de amparo.

Con relación a la primera, su regulación normativa se halla en el art. 323 del Código procesal Civil y Comercial de la Nación y tiene por finalidad asegurar a las partes la oportunidad de plantear sus pretensiones y excepciones o defensas (KIELMANOVICH, 2013).

Al respecto, se evidencia el problema acerca si la enunciación contenida en dicha cláusula es o no taxativa. Quienes se inclinan por la negativa sostienen que el juez puede a su criterio admitir otras distintas a las contempladas por la norma "en tanto y en cuanto ello resulte o aparezca como imprescindible para poder emplazar correcta y útilmente la demandada o su contestación" (KIELMANOVICH, 2013). Ello, siempre teniendo en consideración que la procedencia de la diligencia preliminar está subordinada al futuro inicio de un juicio de conocimiento y esencialmente tiene por objeto asegurar o conservar pruebas.

${ }^{30}$ Conf., Sala II, 03/06/2008, "Taboada Mussi Mirta Fernanda c/TBA SA (Trenes de Buenos Aires SA) s/Amparo por mora", causa N ${ }^{\circ} 1243 / 2007$.

REVISTA DO DIREITO UNISC, SANTA CRUZ DO SUL No. 44 | p.192-219 | SET-DEZ 2014 
También, puede pensarse en la procedencia de una demanda autónoma de información, sea que se utilice la vía ordinaria o abreviada. A esos efectos, cabe traer a colación el fallo de la Sala IV de la Cámara en lo Contenciosoadministrativo federal en la causa "Asociación del personal legislativo c/ Estado nacional - H. Congreso de la Nación- H. Senado-ley 23.551 s/ diligencia preliminar" ${ }^{\prime 1}$. Allí, si bien el tribunal entendió que la solicitud no encuadraba como diligencia preliminar en la medida en que no cumplía los requisitos que ella presupone, no obstante entendió en aplicación del principio iura novit curia, que debía ser encuadrada como demanda autónoma fundada en el derecho de acceso a la información pública reconocida en los arts. 1, 33, 41 y 42 de la Constitución Nacional ${ }^{32}$. Es decir, el tribunal reencuadró la acción con fundamento en la autosuficiencia del pedido de información y en la ausencia de vinculación con la promoción de un concreto proceso futuro.

En cuanto a la utilización de la acción de amparo, en el aludido fallo "ADC", se entiende que ese es el cauce de tutela del DAIP. Si bien, ese remedio puede parecer de manera apriorística la mejor solución no podemos soslayar que la utilización de esa vía puede provocar discusiones que vayan en desmedro de cauce escogido por el requirente de la información. Nos referimos a la cuestión del plazo de caducidad para promover la acción, de la existencia de vías judiciales más idóneas, de la necesidad de mayor debate y prueba, la posibilidad de rechazo in limine, etc.

Podrá pensarse, también, que existiendo una vía judicial especifica fijada por el ordenamiento aplicable a la especie (amparo por mora) el amparo genérico queda desplazado como mecanismo de tutela del derecho a la información pública en tanto el cauce del art. 43 de la $\mathrm{CN}$ queda excluido por la existencia de una vía judicial más idónea.

A pesar de ello, la jurisprudencia sigue entendiendo que es el amparo constitucional la vía correcta y útil para lograr el acceso a la información pública,

\footnotetext{
${ }^{31}$ Sentencia del 3/06/2004, Revista de derecho administrativo $N^{\circ} 52$, Abeledo Perrot, ps. 286 y ss.

${ }^{32}$ En efecto, sostuvo en el considerando IV que no se encontraban reunidas las exigencias para la excepcional vía procesal intentada y que "...resulta que la parte actora persigue tomar conocimiento de los "Decretos de Presidencia, con las designaciones de personal de ambas plantas (transitoria y permanente) y [...] las modificaciones realizadas en las estructuras del Honorable Senado, por el período del año en curso (2002), promociones, subrogancias, designaciones extraescalafonarias y modificaciones de la estructura orgánica”. Ídem, p. 286.
} 
en tanto existe una afectación de derechos constitucionales del más alto rango del interesado ${ }^{33}$.

\section{LA INFORMACIÓN PÚBLICA POSITIVA}

En primer lugar, debe tenerse presente que cuando nos referimos a “información pública positiva” hacemos alusión a la obligación estatal de poner en conocimiento de la ciudadanía -por motu proprio o por imperio legal- la información pública.

Cabe destacar, que este novedoso enfoque del DAIP, que ya está siendo utilizado en el derecho comparado, acrecienta el papel de esta herramienta como cauce de participación ciudadana en los asuntos públicos y como mecanismo para lograr la trasparencia gubernamental.

a) Aspectos generales: En estos casos, la publicidad de la información estatal ya no depende de la inquietud del interesado sino que es producto de un mandato normativo o de la propia decisión estatal.

Así, los Estados que procuran alcanzar mayores niveles de transparencia y reducir la corrupción adoptan conductas proactivas destinadas a poner en conocimiento de los habitantes la actividad estatal. Sino son los propios órganos legisferantes quienes consagran normativamente esa obligación y cuál es la información que debe darse a conocer así como su periodicidad. Es muy importante, en ambos supuestos, que la información nueva se publicite con cierta frecuencia y que se actualice la ya existente.

Esas normas que regulan la obligación estatal de poner en conocimiento de la ciudadanía cierta información acuden a la noción de "obligación mínima" cuyo contenido será establecido por cada organismo estatal o supranacional, según corresponda. A los fines de su determinación, debe acudirse a otra noción que es la de "relevancia" que aparece, de ese modo, como el factor determinante del deber del Estado de hacer pública la información. Como podrá advertirse, se trata de un concepto jurídico indeterminado ${ }^{34}$ que deja sujeto a la valoración de la

${ }^{33}$ Cam. Nac. Fed. Cont. Adm, Sala III, 27/05/2005, "Centro de Implementación de Políticas Públicas E. y C. y otro c/ Honorable Cámara de Senadores del Congreso de la Nación"; Idem, 17/12/97, "Tiscornia Sofía y otro c/ E.N. (M. del Interior) y otro s/ amparo ley 16.986". 
administración pública la determinación de enunciado, con el consiguiente control judicial ${ }^{35}$.

De esta manera, se recomienda que la autoridad administrativa por su propia iniciativa y cuando lo considere apropiado, adopte las medidas necesarias para poner en conocimiento de la ciudadanía la información que sea "de interés" o "relevante" para promover la trasparencia y eficacia de la administración (GUICHOT, 2003) y que se asegure que la misma sea accesible y comprensible (VALLEFIN, 2009). Como podrá advertirse, esta nueva modalidad de acceder a la información permite, además, reducir la conflictividad que presenta el pedido de la información por la parte interesada.

La información pública positiva se asienta en dos pilares básicos. Por un lado, en la capacitación a los empleados estatales para el manejo de la información y sus diversos mecanismos de acceso y en la consiguiente responsabilidad de los funcionarios públicos que tienen a cargo difundir la información. Por el otro, en la creación de oficinas estatales que hagan un seguimiento de la labor de las autoridades públicas y un control de la calidad, completitud y veracidad de la información que se da a conocer.

b) Medios: Es importante tener en cuenta que este concepto de información pública positiva exige no solo la divulgación de la información sino también de los medios para acceder a ella adquiriendo relevancia a esos efectos el uso e implementación por parte de las administraciones públicas de las nuevas tecnologías a los fines de facilitar el acceso y el ejercicio de este derecho constitucional.

Como vimos, el Estado deberá ir colocando gradualmente la información pública en registros y se permitirá su acceso a través de la Internet o la difundirá a través de medios electrónicos. De este modo, la tecnología aparece como un instrumento para acercar la administración al ciudadano y para permitir el

\footnotetext{
${ }^{34}$ Consisten en definiciones genéricas efectuados por el ordenamiento administrativo que para aplicarse a un caso concreto requieren ser interpretadas por el Poder Judicial dado que muchas veces se refieren a realidades extrajurídicas no precisadas en norma alguna (Cfr. SÁNCHEZ MORON, M., Derecho administrativo, op. cit, pag. 92)

${ }^{35}$ En esos casos, la labor del juez estará destinada a comprobar si la valoración efectuada por el poder administrador se corresponde con lo establecido por la norma y advertir -de ese modo- si la administración se ha equivocado o no en la aplicación del concepto al caso concreto.
}

REVISTA DO DIREITO UNISC, SANTA CRUZ DO SUL NN. 44 | p.192-219 | SET-DEZ 2014 
crecimiento de la transparencia. También, puede utilizarse el Boletín Oficial o los medios de comunicación pública.

c) El derecho supranacional: La cuestión que venimos analizando, incluso, ha sido regulada en el plano internacional por la Convención de Naciones Unidas contra la corrupción, la cual ha sido ratificada por nuestro país, lo que hace aplicables sus preceptos habida cuenta su carácter operativo ${ }^{36}$, salvo en materia penal ${ }^{37}$.

Dicho instrumento prevé en el atr. 10 que "Habida cuenta de la necesidad de combatir la corrupción, cada Estado Parte, de conformidad con los principios fundamentales de su derecho interno, adoptará las medidas que sean necesarias para aumentar la transparencia en su administración pública, incluso en lo relativo a su organización, funcionamiento y procesos de adopción de decisiones, cuando proceda. Esas medidas podrán incluir, entre otras cosas: a) La instauración de procedimientos o reglamentaciones que permitan al público en general obtener, cuando proceda, información sobre la organización, el funcionamiento y los procesos de adopción de decisiones de su administración pública y, con el debido respeto a la protección de la intimidad y de los datos personales, sobre las decisiones y actos jurídicos que incumban al público; b)La simplificación de los procedimientos administrativos, cuando proceda, a fin de facilitar el acceso del público a las autoridades encargadas de la adopción de decisiones; y c) La publicación de información, lo que podrá incluir informes periódicos sobre los riesgos de corrupción en su administración pública”.

Por otra parte, el art. 13 dispone que "Cada Estado Parte adoptará medidas adecuadas, dentro de los medios de que disponga y de conformidad con los principios fundamentales de su derecho interno, para fomentar la participación activa de personas y grupos que no pertenezcan al sector público, como la sociedad civil, las organizaciones no gubernamentales y las organizaciones con base en la comunidad, en la prevención y la lucha contra la corrupción, y para sensibilizar a la opinión pública con respecto a la existencia, las causas y la gravedad de la corrupción, así como a la amenaza que ésta representa. Esa

${ }^{36}$ Para Manfroni la operatividad no es inmediata en materia penal (MANFRONI, Carlos A., La convención interamericana contra la corrupción, anotada y comentada, Buenos Aires, Abeledo Perrot, 2001, $2^{\text {a }}$ Ed. act. pag. 112)

37 Cf. GORDILLO, Agustín, Tratado de Derecho administrativo, Buenos Aires, Fundación de Derecho administrativo, $5^{\text {a }}$ Ed. T. I, pag. XVI, 19.

REVISTA DO DIREITO UNISC, SANTA CRUZ DO SUL NN. 44 | p.192-219 | SET-DEZ 2014 
participación debería reforzarse con medidas como las siguientes: a) Aumentar la transparencia y promover la contribución de la ciudadanía a los procesos de adopción de decisiones; b) Garantizar el acceso eficaz del público a la información; c) Realizar actividades de información pública para fomentar la intransigencia con la corrupción, así como programas de educación pública, incluidos programas escolares y universitarios; d) Respetar, promover y proteger la libertad de buscar, recibir, publicar y difundir información relativa a la corrupción".

d) El derecho comparado: Cabe destacar que esta modalidad, que todavía no ha sido receptada en el ordenamiento federal argentino ha tenido interesantes resultados en el derecho comunitario europeo ${ }^{38}$ y en el ámbito del derecho comparado $^{39}$.

En tal sentido, el art. 5 de la Ley 18.381 de Uruguay señala que "Los sujetos obligados deberán prever la adecuada organización, sistematización y disponibilidad de la información en su poder, asegurando un amplio y fácil acceso a los interesados. Los organismos públicos, sean o no estatales, deberán difundir en forma permanente, a través de sus sitios web u otros medios que el órgano de control determine, la siguiente información mínima: a) Su estructura orgánica; b) Las facultades de cada unidad administrativa; c) La estructura de remuneraciones por categoría escalafonaria, funciones de los cargos y sistema de compensación; d) Información sobre presupuesto asignado, su ejecución, con los resultados de las auditorías que en cada caso corresponda; e) Concesiones, licitaciones, permisos o autorizaciones otorgadas, especificando los titulares o beneficiarios de éstos; f) Toda información estadística de interés general, de acuerdo a los fines de cada organismo y g) Mecanismos de participación ciudadana, en especial domicilio y unidad a la que deben dirigirse las solicitudes para obtener información".

Por su parte, en Panamá el art. 9 de la Ley de Transparencia en la Gestión Publica y Habeas Data (Ley 6/2002) establece que "En atención al principio de publicidad, las instituciones del Estado están obligadas a tener disponible en forma impresa, en sus respectivos sitios en Internet y a publicar periódicamente,

\footnotetext{
${ }^{38}$ Vgr. En el ámbito de la Unión Europea la Recomendación del Comité de Ministros del 21 de febrero de 2002 sobre acceso a la información oficial

${ }^{39}$ Vgr. Canadá (Acces to Information act) (Cfr. BASTERRA M., op. cit., pag. 215)
} 
información actualizada respecto de los temas, documentos y políticas que a continuación se detallan: 1. El reglamento interno actualizado de la institución. 2. Las políticas generales de la institución, que formen parte de su plan estratégico. 3. Los manuales de procedimientos internos de la institución. 4. La descripción de la estructura organizativa de la institución. 5. La ubicación de documentos por categorías, registros y archivos de la institución, y el funcionario responsable de éstos. 6. La descripción de los formularios y reglas de procedimiento para obtener información de la institución y dónde pueden ser obtenidos. Las instituciones públicas que tienen páginas electrónicas, además de los boletines, estarán obligadas a publicar a través de Internet la información que obliga la presente Ley. La Contraloría General de la República deberá publicar un informe sobre la ejecución presupuestaria, a más tardar dentro de los treinta días posteriores a dicha ejecución. El Ministerio de Economía y Finanzas deberá publicar un informe sobre la ejecución presupuestaria, a más tardar dentro de los treinta días posteriores a tal ejecución".

Por su parte, la Constitución de México en su art. $6^{\circ}$, luego de consagrar el derecho de acceso a la información y proteger su ejercicio, señala en el punto $V$ que "Los sujetos obligados deberán preservar sus documentos en archivos administrativos actualizados y publicarán a través de los medios electrónicos disponibles, la información completa y actualizada sobre sus indicadores de gestión y el ejercicio de los recursos públicos".

e) Objeto: Mas allá de lo que se prevea en la regulación específica y de lo que se derive de los tratados internacionales a los que hicimos alusión mas arriba, entre la información que debe ponerse en conocimiento de los ciudadanos se destaca la siguiente:

1) La organización y distribución de competencias de cada repartición pública, su estructura jerárquica, su domicilio y demás datos que permitan su individualización;

2) La reglamentación interna de cada entidad;

3) La descripción de los formularios, del procedimiento de acceso a la información y las herramientas que pueden utilizarse en caso denegatoria total o parcial; 
4) Clase de archivos que posee cada organismo, de modo de facilitar el acceso;

5) Los mecanismos y procedimientos de adopción de decisiones públicas;

6) Los datos personales que permitan identificar a los funcionarios que integran cada repartición;

7) Las competencias de cada autoridad;

8) Régimen de funcionamiento;

9) Asignación presupuestaria;

10) Concesiones de obras y servicios, habilitaciones concedidas, permisos otorgados.

11) Régimen de contrataciones públicas;

12) Régimen disciplinario.

\section{LOS LINEAMIENTOS DEL DAIP EN EL FALLO “ADC” DE LA CORTE}

De manera reciente la Corte Suprema de Justicia de la Nación ha dictado su primera sentencia ${ }^{40}$ en donde reconoce sin corta pisas y de manera amplia el derecho de acceso a la información pública poniendo sobre el tapete muchos asuntos que hasta el momento eran motivo de discusiones doctrinarias y sentencias de tribunales inferiores.

Se trataba de la acción de amparo promovida por la Asociación por los Derechos Civiles (ADC) en contra del Instituto Nacional de Servicios Sociales para Jubilados y Pensionados (PAMI) con el objeto de que se hiciera entrega de la información relativa a cómo dicha entidad repartía la pauta oficial.

El eje central de la contienda ronda en torno a las posibilidades de aplicación del Decreto 1172/03 a la demandada en tanto su carácter de persona pública no estatal. El Alto Tribunal entiende que al tratarse de un derecho constitucional netamente operativo debe permitirse el acceso a la información con independencia de que existan normas al respecto. Por tales motivos, consideró

${ }^{40}$ C.S.J.N., 04/12/2012, "Asociación Derechos Civiles el EN - PAMI - (dto.1172/03) s/ amparo ley 16.986", A. 917. XLVI. 
que aquel decreto se aplica a todos de manera supletoria en la medida en que carezca de regulación.

Para concluir de tal modo sostuvo que "aun cuando el recurrente no posea naturaleza estatal, dadas sus especiales características y los importantes y trascendentes intereses públicos involucrados, la negativa a brindar la información requerida constituye un acto arbitrario e ilegítimo en el marco de los principios de una sociedad democrática e implica, en consecuencia, una acción que recorta en forma severa derechos que son reservados -como se verá- a cualquier ciudadano, en tanto se trate de datos de indudable interés público y que hagan a la transparencia y a la publicidad de gestión de gobierno, pilares fundamentales de una sociedad que se precie de ser democrática."

Asimismo, haciendo incapié en el tema de la legitimación pasiva dispuso que para que los Estados cumplan con su obligación de adecuar su ordenamiento interno a los tratados de derecho humanos "no solo deben garantizar este derecho en el ámbito puramente administrativo o de instituciones ligadas al Poder Ejecutivo, sino a todos los órganos del poder público" para concluir que "Dicha amplitud supone incluir como sujetos obligados no solamente a los órganos públicos estatales, en todas sus ramas y niveles, locales o nacionales, sino también a empresas del Estado, hospitales, las instituciones privadas o de otra índole que actúan con capacidad estatal o ejercen funciones públicas" teniendo como norte el principio de máxima divulgación.

\section{Referencias}

BASTERRA, Marcela, "El habeas data" en AA.VV. Derecho procesal constitucional, (Manili, Pablo L., coord.), Buenos Aires, Edit. Universidad, 2005.

BRUNO DOS SANTOS, Marcelo A., FERNÁNDEZ LAMELA, Pablo M., y LOPEZ OLVERA, Miguel Alejandro, "La participación pública y el acceso a la información: herramientas para mejorar la calidad institucional. Comentarios al Decreto 1.172/03", Revista RAP, n³15, pag. 91 y ss, 2006.

BUTELER, Alfonso y CORVALAN, Juan G, “'Los principios del procedimiento informativo", El Derecho, Suplemento de Derecho Administrativo, 18/12/2008, pag. $1 / 4$. 
CARRANZA TORRES, Luis y PALAZZI, Pablo I., "Derecho de acceso a la información pública y derecho de acceso a la información privada (habeas data): semejanzas y diferencias", J.A. 2003-IV, pag. 68.

COMADIRA, Julio Rodolfo, Procedimientos Administrativos, Ley Nacional de Procedimientos Administrativos, Anotada y Comentada, La Ley, Buenos Aires, 2002.

COMADIRA, Julio Rodolfo, "La actividad discrecional de la Administración Pública. Justa medida del control judicial” en El Derecho, Buenos Aires, 29 de marzo de 2001;

COMADIRA, Julio R., La Licitación Pública (Nociones, Principios, Cuestiones), Depalma, Buenos Aires, 2000.

COMADIRA, Julio Rodolfo, El acto Administrativo en la ley Nacional de procedimientos administrativos, Buenos Aires, La Ley, 2003.

COVIELLO, Pedro J., "La causa y el Objeto del acto administrativo", en Acto Administrativo y Reglamento, Jornadas organizadas por la Universidad Austral, Facultad de Derecho, Buenos Aires, RAP, 2002, pag. 46.

DIAZ CAFFERATA, Santiago, "El derecho de acceso a la información pública: situación actual, y propuestas para una ley", Tesina presentada para acceder al título de Magíster en la Universidad Austral, 2007, Inédita.

ESCOLA, Héctor J., Tratado general de procedimiento administrativo, Buenos Aires, Depalma, 1973.

FIORINI, Bartolomé A., Procedimiento administrativo y recurso jerárquico, Buenos Aires, Abeledo-Perrot, 1971, $2^{\mathrm{a}}$ Ed. ampliada y actualizada.

GAMERO CASADO, Eduardo y FERNÁNDEZ RAMOS, Severiano, Manual básico de derecho administrativo, Madrid, Tecnos, 2007, $4^{\mathrm{a}} \mathrm{Ed}$.

GELLI, María Angélica, Constitución de la Nación Argentina, comentada y concordada, Buenos Aires, La Ley, 2003, $2^{\mathrm{a}}$ Ed. act. y ampl.

GELLI, María Angélica, Constitución de la Nación Argentina, comentada y concordada, Buenos Aires, La Ley, 2003, $2^{\text {a }}$ edición ampliada y actualizada.

GORDILLO, Agustín, Tratado de Derecho administrativo, Buenos Aires, Fundación de Derecho administrativo, $5^{\text {a }} \mathrm{Ed}$. T. I.

GUICHOT EMILIO, "El nuevo derecho europeo de acceso a la información pública”, Revista de la Administración Pública española, № 160 (2003), pág. 291. 
IVANEGA, Miriam M., "El amparo por mora", en A.A.V.V., Amparo, medidas cautelares y otros procesos urgentes en la justicia administrativa, obra conjunta, Juan Carlos Cassagne (Director), Buenos Aires, Lexis Nexis, 2007, pag. 93.

KIELMANOVICH, Jorge L., Código Procesal Civil y Comercial de la Nación, Buenos Aires, Lexis Nexis, 1 ed., 2013.

LAVALLE COBO, Dolores, "Un nuevo avance jurisprudencial en el derecho de acceso a la información pública”, L.L., 2005-D, 847.

MENDEZ, Luis M., y PALAZZI, Pablo A., "Un caso de derecho de acceso a la información pública”, E.D., 180:426, 1999.

MANFRONI, Carlos A., La convención interamericana contra la corrupción, anotada y comentada, Buenos Aires, Abeledo Perrot, 2001, $2^{\mathrm{a}}$ Ed. act.

SÁNCHEZ MORON, Miguel, Derecho Administrativo, Madrid, Tecnos, 2007, $3^{\text {a }}$ Ed.

SANCHEZ MORON, Miguel, "El derecho de acceso a la información en materia de medioambiente", Revista de Administración Pública española, № 137 (1995), pag. 31.

SAMMARTINO, Patricio M.E., "El amparo por mora de la administración" en AA.VV., Derecho procesal constitucional, (Pablo. L. Manili Dir.), Buenos Aires, Ed. Universidad, 2005.

TRAVIESO, Florencio, "El derecho de acceso a la información pública. Principios y fundamentos en un reciente fallo", E.D., 197:297.

VALLEFIN, Carlos A., El acceso a la información pública. Una introducción, Buenos Aires, Ad Hoc, 2009.

ZARINI, Helio J., Derecho constitucional, Buenos Aires, Astrea, 1999, $2^{\text {a }}$ Ed. act. y ampl. 